\title{
Resolving discrepancies between laboratory-determined field capacity values and field water content observations: implications for irrigation management
}

\author{
Steven R. Evett ${ }^{1}$ (1) $\cdot$ Kenneth C. Stone ${ }^{1} \cdot$ Robert C. Schwartz $^{1} \cdot$ Susan A. O'Shaughnessy ${ }^{1} \cdot$ Paul D. Colaizzi $^{1}$. \\ Scott K. Anderson ${ }^{2}$. David J. Anderson ${ }^{2}$
}

Received: 5 April 2019 / Accepted: 25 June 2019 / Published online: 9 July 2019

(C) The Author(s) 2019

\begin{abstract}
The concept of soil water contents at field capacity (FC at $0.33 \mathrm{MPa}$ ) and at wilting point (WP at $15 \mathrm{MPa}$ ) is often used to explain plant water availability and as maximal and minimal limits on observed soil water content. Field observations often differ, however, from laboratory-determined FC and WP water content values. Moreover, as more capable sensors have become available and graphical plots of soil water dynamics have become common, plotting of FC and WP lines on such graphs often reinforces these differences and engenders confusion rather than enlightenment. Resolving this confusion has been greatly eased by the introduction of soil water sensors that encapsulate an entire time domain reflectometry (TDR) system in individual sensor heads and the recent availability of a reader for capturing georeferenced values of the TDR waveform and estimated values of soil volumetric water content (VWC), permittivity, temperature, and bulk electrical conductivity. The present study illustrates the typical confusion with season-long graphs of soil water content that greatly exceed the FC values for individual soil horizons, and it resolves the confusion with concurrent and co-located TDR sensor readings and volumetric soil sampling to ascertain sensor accuracy. It was found that sensor readings were reasonably accurate $\left(\mathrm{RMSE}=0.01 \mathrm{~m}^{3} \mathrm{~m}^{-3}\right.$ ) across a range of textures from fine sandy loam to clay, even though some measurements were up to $0.19 \mathrm{~m}^{3} \mathrm{~m}^{-3}$ larger than FC values. Water contents in a sandy eluviated horizon above a dense clay were larger than FC due to the clay layer impeding water flow and perching water in the sand, augmented by the capillary fringe in the fine sand. Confusion was in part created by plotting water content for four different depths of different textures but plotting the FC and WP values for only one soil texture. Misperception of water available for crops was greatly reduced by converting the water content values to equivalent water depth values for the four soil layers and plotting only the soil water storage depth for the entire profile depth covered by the sensing network. The ambiguity was further reduced by determining the maximum value of soil water storage for the season and calculating soil water depletion by subtracting the maximum value from the soil water storage throughout the season. When this was done, it was easy to see depths of water removed from the soil and needing replacement, and to see the extra soil water depletion that occurred when a plot was not irrigated.
\end{abstract}

\section{Introduction}

Soil water status is a state variable that is often proposed as a key input to irrigation management decision support systems (DSS). Both soil matric potential and volumetric

Communicated by A. Furman.

Steven R. Evett

Steve.Evett@ars.usda.gov

USDA ARS, Bushland, TX, USA

2 Acclima, Inc., Meridian, ID, USA water content (VWC) have been used (Evett et al. 2008). Decisions about irrigation initiation and quantity are typically based on comparison of measured or sensed soil water status to some threshold value (Evett 2007). When VWC is used, then the threshold is often the water content at field capacity or a value called the management allowed depletion (MAD) that is some fraction of the difference between the soil water contents at field capacity (FC) and at permanent wilting point (WP). The FC is understood to be the soil water content after a thoroughly wetted soil has drained for some period of time, typically $24 \mathrm{~h}$. In the laboratory, it is often taken to be the water content of a soil core after a pressure of $0.33 \mathrm{kPa}$ has been applied to a saturated soil 
core. Irrigating to replenish the soil water to field capacity after a crop has taken up water from the soil is considered a best practice, because irrigating more than that would cause the soil to quickly lose water through internal drainage. Irrigating before the VWC declines to the MAD value is considered a best practice to avoid yield loss due to plant water stress. These concepts are appropriate for soils that are relatively uniform with depth and freely draining. However, the water content at field capacity $\left(\mathrm{FC}, \mathrm{m}^{3} \mathrm{~m}^{-3}\right)$ is rarely determined in the field, but rather is determined using a pressure plate apparatus operated to place a core sample under $0.33 \mathrm{kPa}$ pressure. Moreover, many agricultural soils are not uniform with depth and may include horizons that restrict internal drainage.

At the USDA ARS Coastal Plain Soil, Water and Plant Conservation Research Center, Florence, SC, research on variable rate center pivot irrigation was implemented in the mid-1990s (Camp and Sadler 1994). Irrigation management was accomplished using a network of up to 45 tensiometers placed in a 6-ha field under a three-span center pivot (Sadler et al. 1996, 2002). The variable rate system was purpose built by research center personnel (Omary et al. 1997). In 2015, a new Cooperative Research and Development Agreement (CRADA) was reached between ARS and Valmont Industries, Inc. to outfit the center pivot with the Valley variable rate irrigation (VRI) system and to conduct beta tests of an Irrigation Scheduling Supervisory Control and Data Acquisition (ISSCADA) system developed and patented by ARS (Evett et al. 2014). ARS at Florence cooperated in the testing with ARS scientists and engineers at Bushland, TX; Portageville, MO; and Stoneville, MS. The ISSCADA system utilizes wireless infrared thermometers to sense crop canopy temperature, soil water sensors to determine soil water status, and weather sensors to determine solar irradiance, wind speed, humidity, and air temperature.

The ISSCADA software, named ARSPivot (Andrade et al. 2017), runs on an embedded computer at the pivot point, automatically collecting data from the wireless-sensing sources, applying algorithms to determine when, where, and how much to irrigate, and developing a VRI prescription map that is sent to the pivot control panel where it is executed. The algorithms used involve computing an integrated crop water stress index (iCWSI) and comparing it to built-in threshold values. A hybrid algorithm uses the outcome in conjunction with soil water depletion (SWD) data to develop the prescription map. The percent of SWD is calculated using the soil VWC, FC, and WP at each sensor depth. If SWD $<10 \%$, then no irrigation is applied; if SWD $>50 \%$, then irrigation is prescribed at the maximum depth; and if $10 \%<$ SWD $<50 \%$, the iCWSI thresholds are used to determine the irrigation depth. When requested by the user, the software displays water content for every site and for every depth at that site and plots daily, 3-day, week-long, or season-long VWC along with FC and WP values for a specific user-chosen depth (Fig. 1). Note that, in Fig. 1, the water contents for the 15.7-inch (40-cm) depth were always larger than the FC value plotted for that depth. The sensors that were used (model TDR-315L, Acclima, Inc., Meridian, ID) were found to be accurate in the soils at Bushland (e.g., Schwartz et al. 2016). Therefore, the fact that VWC was larger than FC was attributed to water perched above and in the slowly permeable B2t horizon and the inhibition of soil water flux by the abrupt change with depth of pore size between the small pores in the B2t and the larger pores in the calcic Btka horizon underneath.

Research to beta test the ISSCADA center pivot variable rate irrigation (VRI) decision support system (O'Shaughnessy et al. 2015, 2016, 2018) at Florence was conducted in 2017 and 2018. Sensed water contents at given depths were often, even commonly, larger than field capacity values (Fig. 2). The FC values were previously determined by applying tension table and pressure plate methods to soil samples from those depths (Peele et al. 1970). Since the soil surface horizons were predominantly sandy (e.g., $15-\mathrm{cm}$ depth in Fig. 2) and the FC values determined by Peele et al. (1970) seemed reasonable for those textures, this discrepancy called into question the accuracy of the sensors.

A field investigation was conducted at Florence to determine if sensor inaccuracy was causing sensed soil water content to be larger than FC and WP values, to investigate the vadose zone hydrologic factors that might cause sensor readings to deviate from expectations, and to determine if other ways of analyzing and viewing the soil water data might prove more useful for irrigation management.

\section{Materials and methods}

The study was conducted at the USDA ARS Coastal Plain Soil, Water and Plant Conservation Research Center, $2611^{\circ} \mathrm{W}$. Lucas St., Florence, SC. Lat: $34.2447813^{\circ}$, Long: $-79.8076318^{\circ}, 47 \mathrm{~m}$ above MSL) under a three-span center pivot irrigation system. There are 12 soil units under the center pivot (Sadler et al. 2002), mostly loamy fine sands or fine sandy loams in the surface A and eluviated $\mathrm{E}$ horizons above a kaolinitic clay Bt horizon (Paleudults, Paleaquults, and Kandiudults). Similar soils are termed duplex or texture contrast soils in Australia. Depth to clay and the presence or absence of a compacted layer within the sandy horizons are two major factors that affect plant rooting and plant water availability. Depth to clay ranges from 0.23 to $0.55 \mathrm{~m}$ (Sadler et al. 1995). Organic matter content is typically $<2 \%$ by mass and the fine sands are easily compacted (Karlen et al. 1990).

A newly introduced soil water sensor based on time domain reflectometry (TDR) (model TDR-315L with 


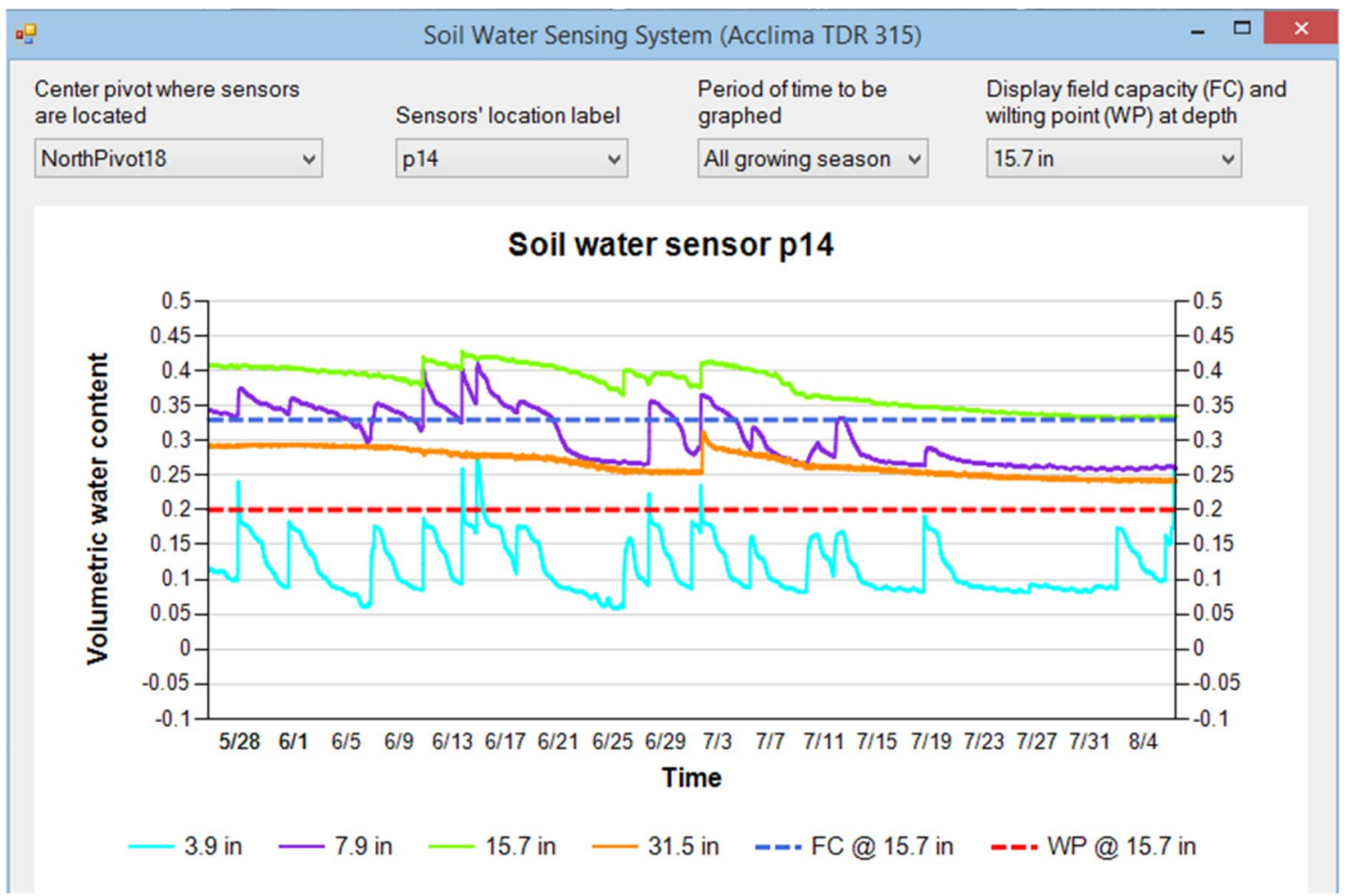

Fig. 1 Screenshot of the ARSPivot software showing season-long volumetric water contents sensed at four depths in 2018 at Bushland, TX. Also plotted are lines for field capacity (FC) and wilting point (WP) water contents for the soil at the 15.7-inch (40-cm) depth

Fig. 2 Volumetric soil water content sensed in plot P1 at Florence, SC, during the 2018 corn growing season. Also plotted are lines representing the field capacity and wilting point water contents of the sandy soil at the $15-\mathrm{cm}$ depth as determined by applying tension table and pressure plate methods to soil cores

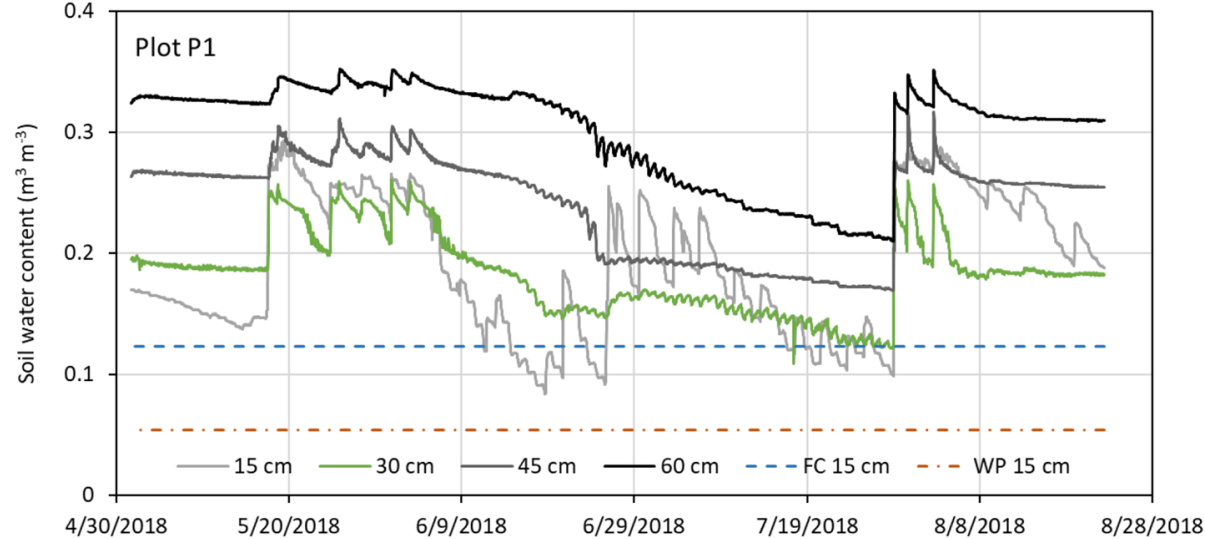

waveform capture, Acclima, Inc., Meridian, ID) and SDI12 sensor reader (model ACC-RD1200, Acclima, Inc.) were used together to sense soil water content at depths of 0.15 , $0.30,0.45$, and $0.60 \mathrm{~m}$ at four locations where soil water sensors had been deployed in the DSS beta tests. The four locations were in two different soil units, both Kandiudults (Table 1). The sensor returns values of volumetric soil water content, relative permittivity, temperature, and bulk electrical conductivity, along with a waveform consisting of values of relative impedance at 5 ps intervals from 0 to $20,475 \mathrm{ps}$ (4096 values). The reader displays these, allowing the user to quickly ascertain if the sensor is working properly and if it has been inserted into the soil properly by examining the waveform displayed by the reader. The reader records these data along with the time of reading and the georeferenced location to within $2 \mathrm{~m}$ for later download. More information about the new sensor and reader is given in Appendix A along with examples of TDR waveforms.

Soil water contents were then determined using standard gravimetric/volumetric methods by inserting a core sampler into the soil in the same soil volume into which the sensor had been inserted and taking an undisturbed soil core. The Madera probe soil sampler used had a $60 \mathrm{~cm}^{3}$ sample volume and was described by Evett (2008). Core samples were 
Table 1 Classification of the soil map units and nearby units where soil samples and sensor readings were taken at the Coastal Plains Research Center

\begin{tabular}{lll}
\hline Symbol/Sample \# & Soil classification & Soil description \\
\hline BnA/Adjacent to P16 and P17 & Bonneau loamy fine sand (Ifs), 0\% to 2\% slopes & Loamy, siliceous, thermic Arenic Paleudult \\
NkA/P1 and P7 & Norfolk Ifs, moderately thick surface, deep water table, & Fine-loamy, siliceous, thermic Typic Kandiudult \\
& $0 \%$ to 2\% slopes & \\
NoA/P16 and P17 & Norfolk Ifs, thick surface, 0\% to 2\% slopes & Fine-loamy, siliceous, thermic Typic Kandiudult
\end{tabular}

Sampling sites are designed P1, P7, P16, and P17. After Sadler et al. (2002)

sealed into plastic bags for later determination of mass to $0.01 \mathrm{~g}$ on a calibrated electronic scale. After oven drying for $24 \mathrm{~h}$ at $105^{\circ} \mathrm{C}$, the core dry mass was determined using the scale, and water content of the core was calculated in $\mathrm{g}$. Assuming a water density of $1 \mathrm{~g} \mathrm{~cm}^{-3}$, the volumetric water content of the core sample was calculated by dividing the water mass value by 60 . Locations were designated P1, P7, P16, and P17 (Fig. 3). Locations P16 and P17 were close to the boundary with another soil unit, an Arenic Paleudult (Table 1).

\section{Results}

Comparison of sensor readings $\left(\mathrm{VWC}_{\text {sensor }}\right)$ with soil water contents determined gravimetrically from core samples $\left(\mathrm{VWC}_{\text {grav }}\right)$ indicated that sensor readings were reasonably accurate $\left(\mathrm{VWC}_{\text {sensor }}=0.911\left(\mathrm{VWC}_{\text {grav }}\right)+0.027, r^{2}=0.96\right.$, $\mathrm{RMSE}=0.01 \mathrm{~m}^{3} \mathrm{~m}^{-3}$, Fig. 4). This result opens up questions as to: (1) why the sensed water contents during the 2018 growing season were so much larger than FC; and (2) Were the previously determined FC and WP values incorrect? Also called into question is the usefulness for irrigation management of comparing sensed soil water content to FC and WP values, particularly in layered soils.

Re-examining the data for plot P1 shown in Fig. 2 shows that the water content at $15-\mathrm{cm}$ depth and the water content at $60-\mathrm{cm}$ depth were both much greater than FC for most of the growing season. Results for 30- and 45-cm depths were similar, but, to avoid making the graphs too busy, the FC values were not plotted. The same was true for water contents sensed in 2018 at P7. At both P1 and $\mathrm{P} 7$, the soil at 15- and 30-cm depths is sandy and the soil at $45-$ and $60-\mathrm{cm}$ depths is clayey. A period of plentiful precipitation beginning on 17 May 2018 and continuing through 3 June 2018 brought soils in both the sand and clay to well above FC values, and periodically to close to saturation (Fig. 5). As expected, the sandier layers at 15- and 30-cm depths exhibited smaller maximum water contents (typically $<0.3 \mathrm{~m}^{3} \mathrm{~m}^{-3}$ ) than the more clayey soils at 45 and $60-\mathrm{cm}$ depths $\left(>0.3 \mathrm{~m}^{3} \mathrm{~m}^{-3}\right)$. The soil at $30-\mathrm{cm}$ depth was in the zone of a plow pan and exhibited

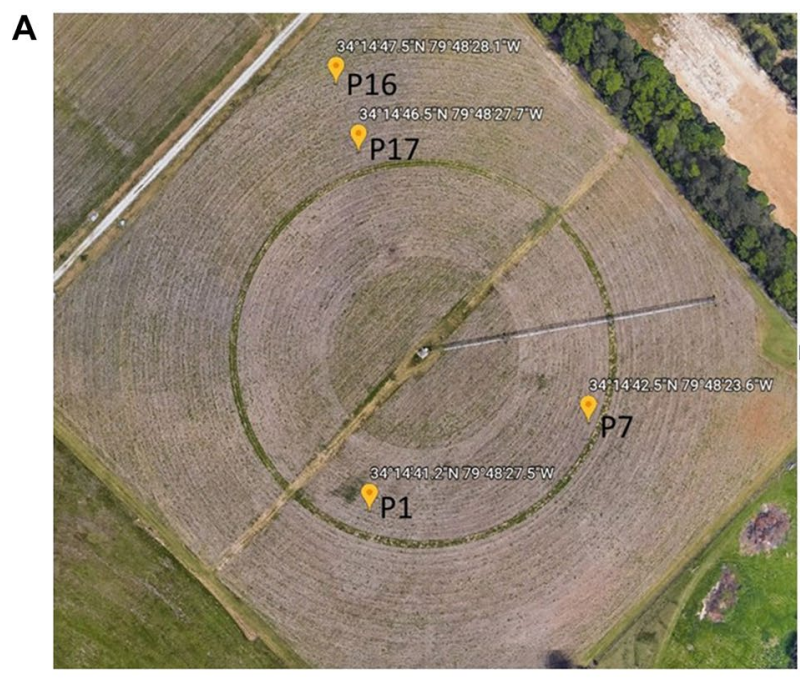

B

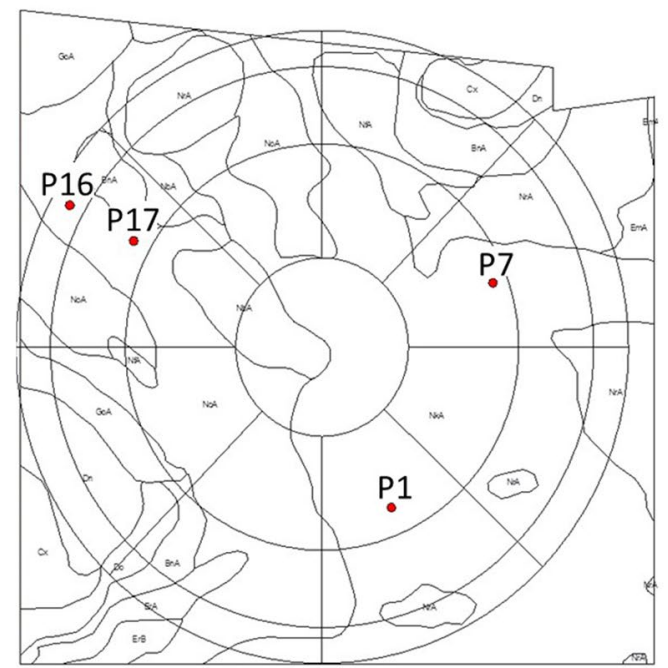

Fig. 3 a Locations of soil sensing and sampling at the USDA ARS Coastal Plain Soil, Water and Plant Conservation Research Center, Florence, SC. b Sampling locations overlaid with soil unit map. The four sampling locations were labeled P1, P7, P16, and P17. P1 and P7 are in NkA, and P16 and P17 are in NoA, but close to the border with BnA. Note that (b) is rotated $\sim 45^{\circ}$ counterclockwise relative to (a)

a greater bulk density (mean: $1.74 \mathrm{~g} \mathrm{~cm}^{-3}$ ) and smaller maximum water content than the soil at $15-\mathrm{cm}$ depth (mean: $1.57 \mathrm{~g} \mathrm{~cm}^{-3}$ ) or in the deeper clay. The soil at 
TDR-315L vs. Volumetric soil samples

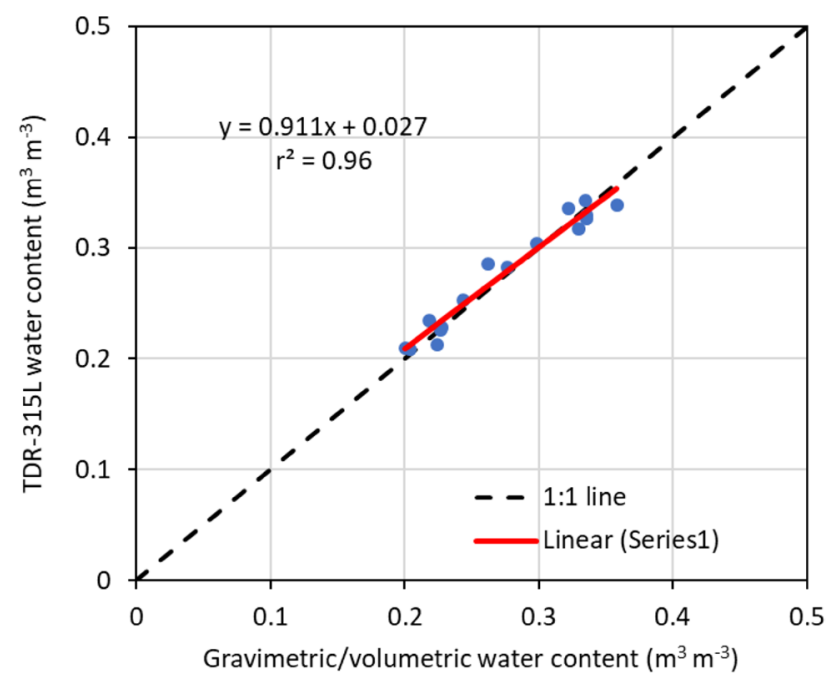

Fig. 4 Linear regression analysis of readings from the TDR-315L waveform sensor versus soil water contents determined gravimetrically from $60 \mathrm{~cm}^{3}$ undisturbed soil cores

60-cm depth had the largest percentage of clay, smaller bulk density, and somewhat larger maximum water content than the soil at 45-cm depth. After 3 June 2018, the clay horizon continued to inhibit free drainage of the sands above it, and water content in the sand did not decrease to
FC until 15 June. The growing corn crop did extract water from all depths, although more so from the $15-$ and $30-\mathrm{cm}$ depths. Extraction from the 45- and 60-cm depths accelerated after water was extracted from the sandy layers until a large precipitation event on 26 June temporarily slowed extraction at those depths. Irrigations on plot P1 after 26 June replenished water in the sand and slowed extraction at $45-$ and $60-\mathrm{cm}$ depths. In plot P7, the lack of irrigations caused accelerated extraction of water at $45-$ and $60-\mathrm{cm}$ depths, and caused water content at $15 \mathrm{~cm}$ to decrease to less than FC by 2 July. A large (>120 mm) precipitation event on 29 July associated with a tropical depression off the coast caused flash flooding in Florence, ended the irrigation season, and again brought water contents to near saturation.

In contrast to the soils at sites $\mathrm{P} 1$ and $\mathrm{P} 7$, the soil at site P17 was sandy at depths of 15,30 , and 45 and to just above the $60-\mathrm{cm}$ depth, where a clay horizon was apparent. Also contrasting with P1 and P7, the soil water contents at P17 were more often less than FC, the exception being the water content at $45-\mathrm{cm}$ depth, which was almost always greater than the FC value for that depth (Fig. 6). We conjecture that the deep sand was more freely draining (perhaps laterally as well), allowing water contents nearer the surface to regularly decrease to closer to and sometimes less than FC despite the irrigations occurring after 26 June. Reinforcing this view was the fact that the sand
Fig. 5 Water contents sensed in a plot P1 and b plot P7 in 2018. Also plotted are the field capacity water contents for soils at P1 and P6 at depths of 15 and $60 \mathrm{~cm}$
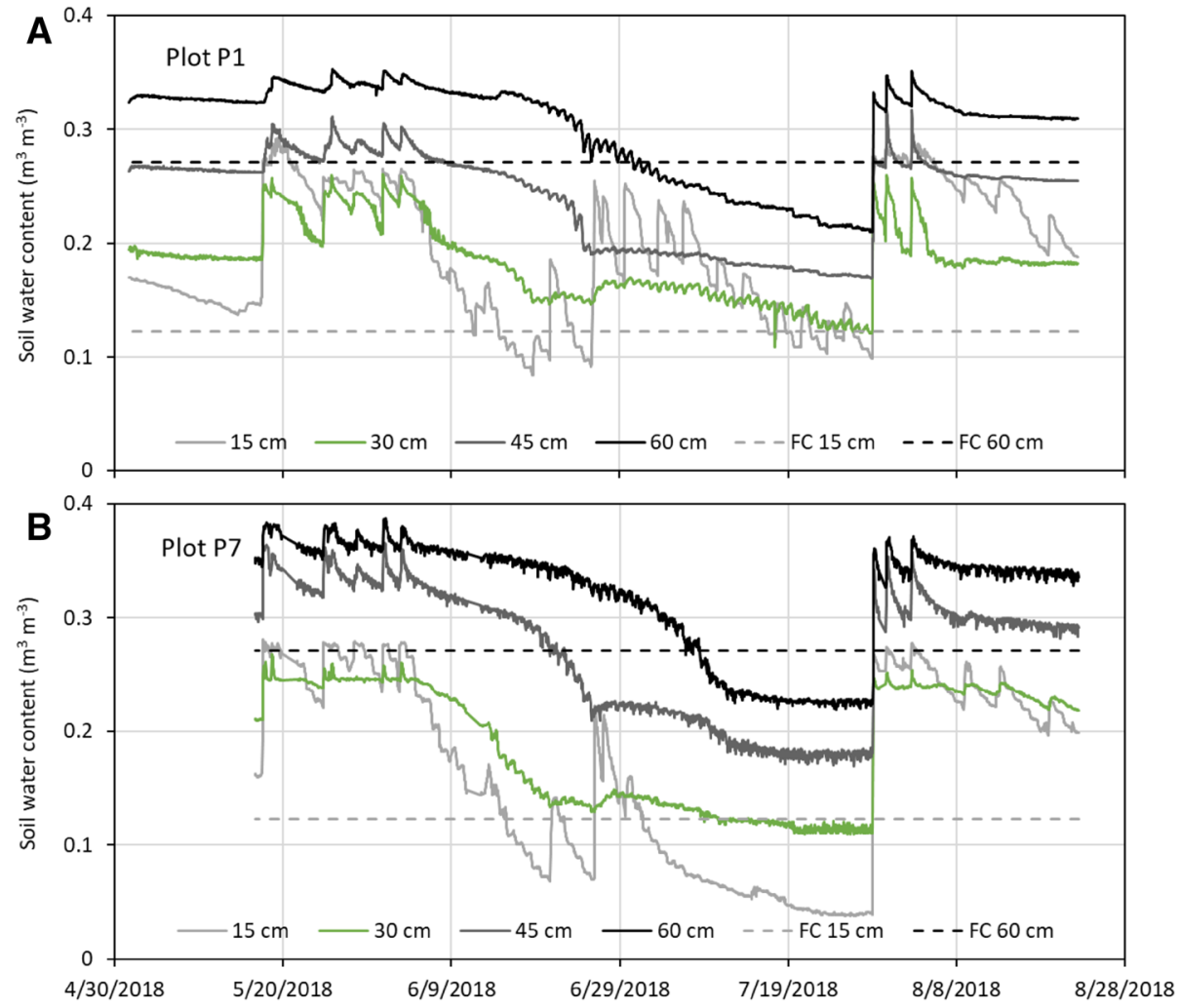
Fig. 6 Soil water content sensed at plot P17 at depths of 15,30 , 45 , and $60 \mathrm{~cm}$ in sandy soils. Also plotted are field capacity water contents for soil samples taken at depths of 15,45 , and $60 \mathrm{~cm}$. The field capacity at $30 \mathrm{~cm}$ was close to that for $45 \mathrm{~cm}$

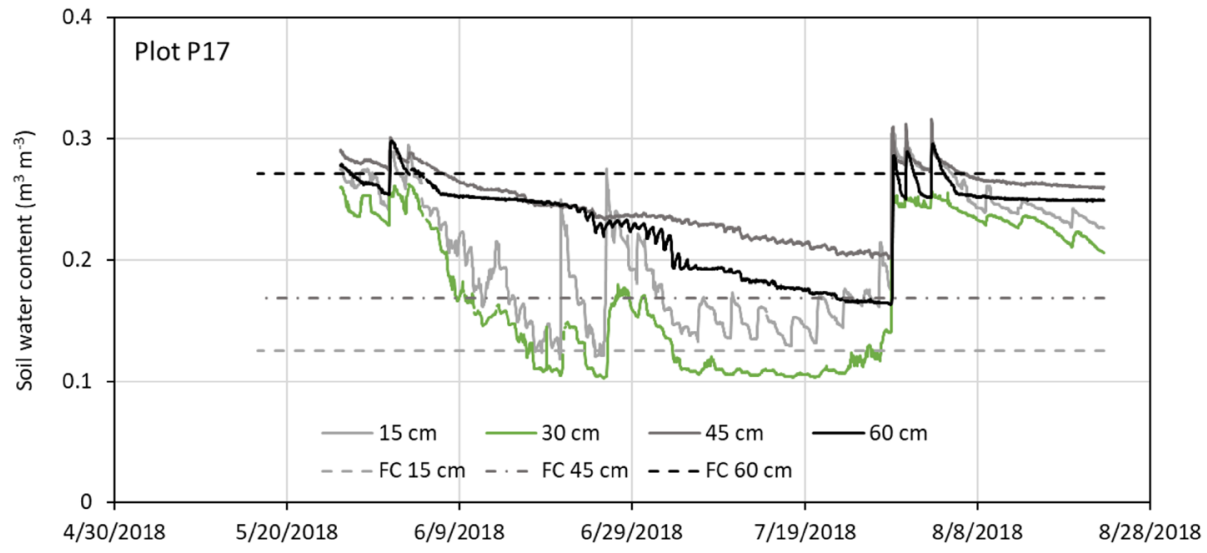

just above the clay at $60 \mathrm{~cm}$ was saturated when the pit was dug for soil sampling. Data for site P16 are not shown due to a sensor failure, but were similar in dynamics to data from the other three sites.

\section{Discussion}

The analysis presented so far is somewhat limited by the use of soil property data obtained in the previous studies to explain the behavior of soils in the same field at particular locations mapped to the soil units to which those properties pertain. Nonetheless, it is clear that field capacity values from laboratory analyses are not very useful for explaining the water status of these soils for irrigation management. Impeding layers and resultant soil water dynamics rule the outcomes of precipitation, irrigation, and crop water uptake. Assuming that the water content sensed at each depth is representative of the soil from that depth to the midpoint between that and both the next upper and lower depths of sensing allows calculation of the soil water storage in the profile (Fig. 7a). Doing so reveals a more consistent view of soil water relations than simply plotting the soil water contents versus FC. Using the maximal soil profile water
Fig. 7 a Soil water storage and b soil water depletion in the surface to 67.5 -cm deep profile at three sites under a three-span variable rate center pivot during the corn growing season at the USDA ARS Coastal Plain Soil, Water and Plant Conservation Research Center, Florence, SC. Data for plot P16 were not plotted due to lack of data at one depth for most of the season
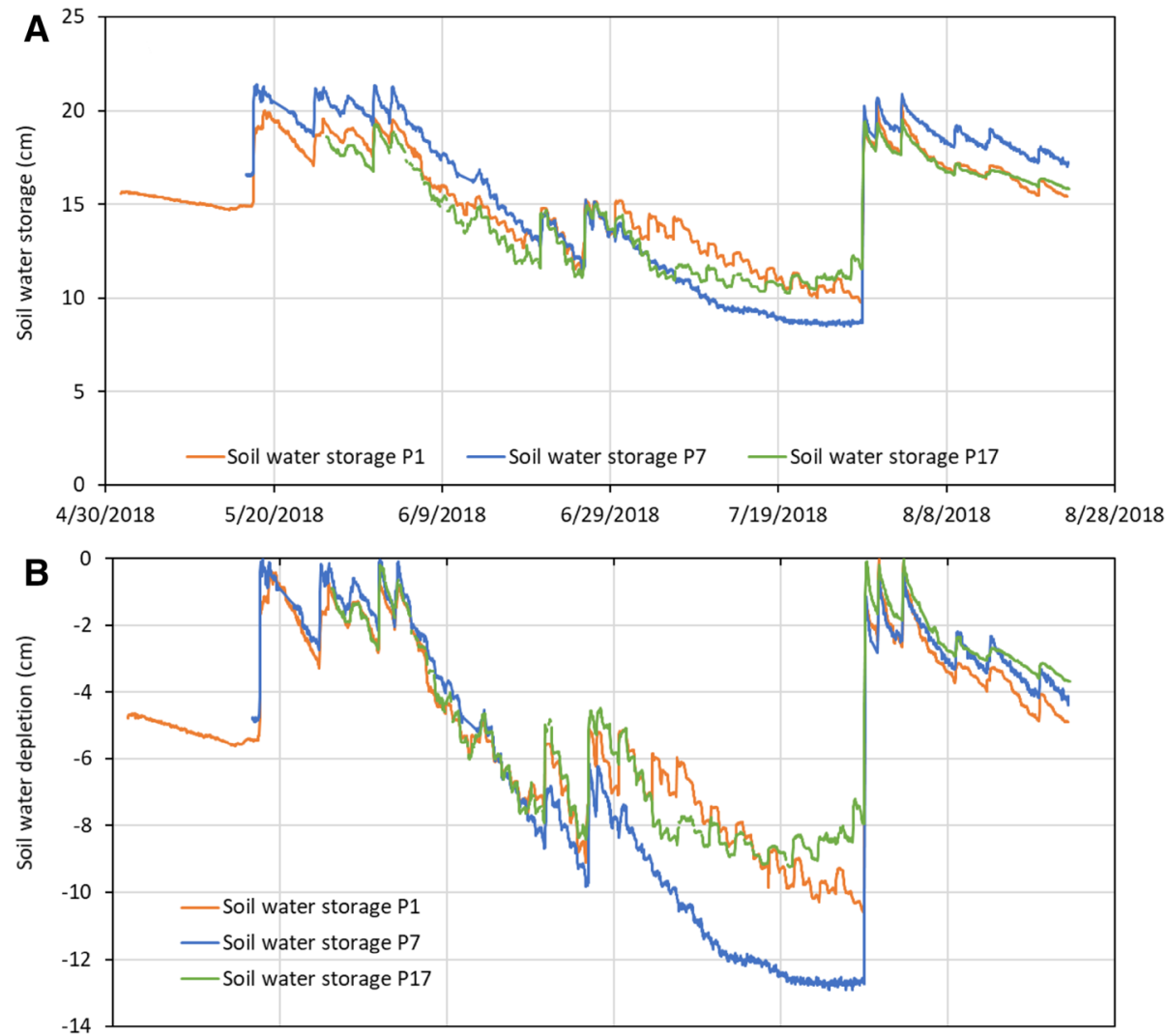
contents as a reference point for a full profile and calculating the soil water depletion from that value for each plot revealed an even more consistent view of the soil water response to precipitation, irrigation, and crop water uptake (Fig. 7b). Data from plots P1 and P17, which received irrigation after 26 June, plotted closely to each other, and data from plot P7 showed the greater depletion due to the lack of irrigation on that plot during the period from 26 June until the precipitation event on 29 July 2018.

The analysis presented in Fig. $7 \mathrm{~b}$ has three advantages. First, it allows sensing of the soil at specific sites in the field to dictate the upper bound of soil water storage. Second, using that upper bound, it allows the soil water depletion and values of possible irrigation depths to be easily seen and understood. Third, it avoids the confusing picture obtained when comparing sensed soil water contents to laboratorydetermined values of field capacity. For example, comparing Fig. 5a for plot P1 and Fig. 6 for plot P17, one might conclude that the two plots had entirely different soil water conditions and that plot P17 was likely much shorter of water than plot P1. By comparison, the analysis illustrated in Fig. 7b shows that soil water status for plots P1 and P17 was nearly the same. The ARSPivot software will be modified to show a single line of soil water depletion over time, replacing the confusing plotting of water contents at multiple depths. Still missing from this analysis is information about the management allowed depletion (MAD) level. However, in the DSS represented by ARSPivot irrigation, scheduling decisions are based on an integrated crop water stress index (CWSI) calculated from crop canopy temperature data, not on an MAD value. In the ISSCADA system, the soil water data are used as limiting factors rather than the primary data for irrigation decisions. The relationship between CWSI and plant available water is strong but not straightforward (Evett et al. 2016). Approaches that integrate CWSI with soil water balance and root water uptake modeling may allow estimation of total plant available water in a soil profile and a useful approximation of MAD or a similar index (e.g., Han et al. 2018; Shi et al. 2015; Wu et al. 2017).

\section{Conclusions}

Although the determination of field capacity (FC) and wilting point (WP) water contents using soil cores and pressure plate/ tension table apparatus is a time-honored practice, the FC and WP values so determined may not be directly useful for irrigation management based on field measured soil water content data. This does not mean that we should discontinue laboratory determination of FC and WP. These values may be useful in estimation of soil hydraulic characteristics that are be used to model soil water flux and crop water uptake dynamics in multilayer simulation models, including those used for irrigation management. As accurate soil water sensors and continuous data logging become more available, discrepancies between field-determined water content data and FC [as well as WP and management allowed depletion (MAD)] values will become more evident, forcing us to evaluate soil water status in ways that are more relevant to the soil profile within the rhizosphere rather than with regard to individual soil layers. Calculating the profile water storage and in particular the profile water depletion are ways to interpret water content data from sensors at multiple depths that may be more relevant to irrigation management. In this regard, it is important to note that soil water depletion is strongly related to crop water uptake and the rooting pattern of the crop, giving plots of soil water depletion special relevance to crop water use and need. Further research is needed to see how the MAD limit may be integrated into soil water depletion plots, but simulations of soil water balance and root water uptake can play a role, particularly if accurate soil water content data are routinely available for assimilation into and real-time correction of such simulations.

Acknowledgements This material is based in part upon work that is supported by the National Institute of Food and Agriculture, U.S. Department of Agriculture, under award number 2016-67021-24420. Work reported in this paper was also accomplished as part of a Cooperative Research and Development agreement between USDA-ARS and Acclima, Inc. (Agreement No. 58-3090-9-001). We acknowledge support from the USDA-ARS Ogallala Aquifer Program, a consortium between the USDA Agricultural Research Service, Kansas State University, Texas A\&M AgriLife Research, Texas A\&M AgriLife Extension Service, Texas Tech University, and West Texas A\&M University, as well as the dedicated support of Karen Copeland, USDA-ARS Soil Scientist, and Brice Ruthardt, USDA-ARS Biological Scientist. The U.S. Department of Agriculture (USDA) prohibits discrimination in all its programs and activities on the basis of race, color, national origin, age, disability, and where applicable, sex, marital status, familial status, parental status, religion, sexual orientation, genetic information, political beliefs, reprisal, or because all or part of an individual's income is derived from any public assistance program (not all prohibited bases apply to all programs). Persons with disabilities who require alternative means for communication of program information (Braille, large print, audiotape, etc.) should contact USDA's TARGET Center at (202) 7202600 (voice and TDD). To file a complaint of discrimination, write to USDA, Director, Office of Civil Rights, 1400 Independence Avenue, S.W., Washington, D.C. 20250-9410, or call (800) 795-3272 (voice) or (202) 720-6382 (TDD). USDA is an equal opportunity provider and employer. The mention of trade names of commercial products in this article is solely for the purpose of providing specific information and does not imply recommendation or endorsement by the U.S. Department of Agriculture.

Data availability Some or all data, models, or code generated or used during the study are available from the corresponding author by request (data for graphs and soil samples).

Open Access This article is distributed under the terms of the Creative Commons Attribution 4.0 International License (http://creativeco mmons.org/licenses/by/4.0/), which permits unrestricted use, distribution, and reproduction in any medium, provided you give appropriate credit to the original author(s) and the source, provide a link to the Creative Commons license, and indicate if changes were made. 


\section{Appendix A: Waveform data from the TDR-315L waveform sensor}

The new TDR-315L Waveform Sensor and Sensor Reader (model ACC-RD1200, Acclima, Inc.) allowed facile collection of TDR and ancillary data during this experiment. When reading a sensor, one may choose to obtain either the sensor readings only or the sensor readings and the waveform data in just a few seconds. The Reader stores the data in CSV file format, which may be read by Excel and converted to an Excel worksheet. Stored are the date, time, sensor serial number, latitude, longitude, sensor model, volumetric water content (units of \%), soil temperature $\left({ }^{\circ} \mathrm{C}\right)$, apparent permittivity, and bulk electrical conductivity followed by 4096 values of relative impedance at 5 ps time intervals (from 0 to 20,475 ps). The Sensor Reader displays these data on a sunlight readable LCD screen. Importantly, viewing the waveform allows the user to ascertain if the sensor electrodes were inserted into the soil correctly, so that the sensor can be pulled out and reinserted if necessary to obtain good data. Although the reader is optimized to work with the new TDR-315L and TDR-315H waveform sensors, it is backwards compatible with earlier versions of the TDR$315 \mathrm{~L}$ and TDR-310S sensors. Although waveform capture is not possible with the earlier sensor versions, all the other parameters are recorded when one of those sensors is read.

Figure 8 illustrates the plots of TDR waveforms acquired at depths of 15, 30, 45, and $60 \mathrm{~cm}$ at four field sites (P1, P7, P16, and P17) at the USDA ARS Coastal Plain Soil, Water and Plant Conservation Research Center, Florence, SC. Waveforms were clean and similar to those from a conventional TDR system based on, for example, a Tektronix 1502C TDR instrument and TDR probe (Evett 2003). They could be analyzed using TDR waveform analysis programs such as TACQ (Evett 2000). Waveforms from the $60-\mathrm{cm}$ depth exhibited the largest travel times and water contents (water content is practically linear with travel time, Evett et al. 2005). Waveforms from the $15-\mathrm{cm}$ depth reflected nearly the smallest travel times and water contents, although, for plots 16 and 17, the water content at 30-cm depth was slightly smaller. The deepest sand was at plot 17 , which is reflected in the smaller travel times at 15-, 30-, and 45-cm depths. The reading at $60-\mathrm{cm}$ depth in plot 17 was in clay, which is reflected by the larger travel time and water content for that depth. In plot 16, readings at both $45-$ and $60-\mathrm{cm}$ depths were in clay. In plot 7, the $45-$ and $60-\mathrm{cm}$ readings were in clay and the $30-\mathrm{cm}$ reading was in sandier soil. In plot 1 , the $15-$ and $30-\mathrm{cm}$ readings were in sandy soil, and the $45-$ and $60-\mathrm{cm}$ readings were in clayey soil. Note that larger water contents did not indicate only soil texture (clay was typically wetter than sand), but also indicated water perched in the sand above the clay in some instances.
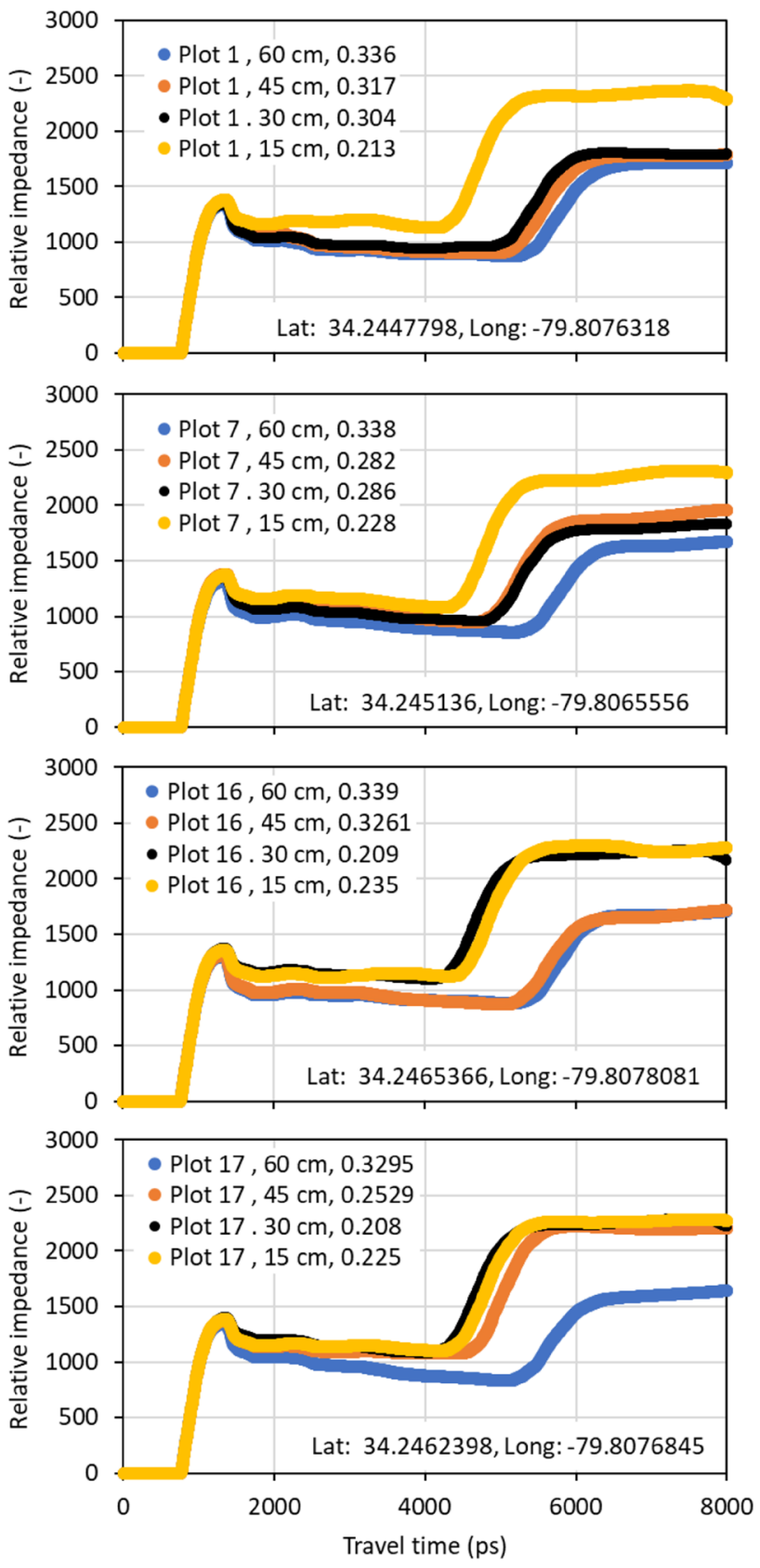

Fig. 8 Plots of TDR waveforms acquired at depths of 15, 30, 45, and $60 \mathrm{~cm}$ at four field sites (P1, P7, P16, and P17) at the USDA ARS Coastal Plain Soil, Water and Plant Conservation Research Center, Florence, SC. Shown in the legends are the plot number, the sampling depth, and the sensed water content in $\mathrm{m}^{3} \mathrm{~m}^{-3}$. Also shown is the latitude and longitude of each site

\section{References}

Andrade MA, O'Shaughnessy SA, Evett SR (2017) Site specific irrigation management of a center pivot irrigation system using a sensor based decision support system. In: Proceedings of 2017 Irrigation Association Technical Conference on, 6-10 Nov 2017, Orange County Convention Center, Orlando, Florida. Irrigation Association, Fairfax, Virginia 
Camp CR, Sadler EJ (1994) Center pivot irrigation system for sitespecific water and nutrient management. ASAE Paper \# 94-1586. 1994 Winter International Meeting, Atlanta, GA, 13-16 Dec, p 9

Evett SR (2000) The TACQ program for automatic time domain reflectometry measurements: II. Waveform interpretation methods. Trans ASAE 43(6): 1947-1956

Evett SR (2003) Soil water measurement by time domain reflectometry. In: Stewart BA, Howell TA (eds) Encyclopedia of water science. Marcel Dekker, Inc., New York, pp 894-898

Evett SR (2007) Soil water and monitoring technology. Pp. 25-84 In R.J. Lascano and R.E. Sojka (ed.) Irrigation of Agricultural Crops. Agron. Monogr. 30, 2nd ed. ASA, CSSA, and SSSA, Madison, WI

Evett SR (2008) Neutron moisture meters. In: Evett SR, Heng LK, Moutonnet P, Nguyen ML (eds) Field Estimation of Soil Water Content: A Practical Guide to Methods, Instrumentation, and Sensor Technology, Chapter 3, IAEA-TCS-30. International Atomic Energy Agency, Vienna, Austria, pp 39-54. ISSN 1018-5518

Evett SR, Tolk JA, Howell TA (2005) TDR laboratory calibration in travel time, bulk electrical conductivity, and effective frequency. Vadose Zone J 4:1020-1029. https://doi.org/10.2136/vzj20 05.0046 (Special Section: Soil Water Sensing)

Evett SR, Heng LK, Moutonnet P, Nguyen ML (eds) (2008) Field estimation of soil water content: a practical guide to methods, instrumentation, and sensor technology. IAEA-TCS-30. International Atomic Energy Agency, Vienna, Austria, ISSN 1018-5518

Evett SR, O'Shaughnessy SA, Peters RT (2014) Irrigation scheduling and supervisory control data acquisition system for moving and static irrigation systems. United States Patent No.: US 8,924,031 B1. 30 Dec 2014

Evett SR, O’Shaughnessy SA, Colaizzi PD, Schwartz RC (2016) Relating soil available water fraction to water stress indices. In: Technical sessions proceedings on, irrigation show and education conference, 5-9 Dec 2016, Las Vegas Convention Center, Nevada. Irrigation Association, Falls Church, Virginia

Han M, Zhang H, Chávez JL, Ma L, Trout TJ, DeJonge KC (2018) Improved soil water deficit estimation through the integration of canopy temperature measurements into a soil water balance model. Irrig Sci 36:187-201. https://doi.org/10.1007/s0027 1-018-0574-z

Karlen DL, Sadler EJ, Busscher WJ (1990) Crop yield variation associated with coastal plain soil map units. SSSAJ 54:859-865

O’Shaughnessy SA, Evett SR, Colaizzi PD (2015) Dynamic prescription maps for site-specific variable rate irrigation of cotton. Agric Water Manag 159:123-138
O'Shaughnessy SA, Evett SR, Andrade A, Workneh F, Price JA, Rush CM (2016) Site-specific variable rate irrigation as a means to enhance water use efficiency. Trans ASABE 59(1):239-249. https ://doi.org/10.13031/trans.59.11165

O'Shaughnessy SA, Andrade MA, Stone KC, Vories ED, Sui R, Evett SR (2018) Adapting a VRI irrigation scheduling system for different climates. In: 2018 Irrigation association show and education conference technical session proceedings on irrigation association, Fairfax, VA

Omary M, Camp CR, Sadler EJ (1997) Center pivot irrigation system modification to provide variable water application depths. Appl Eng Agric 13(2):235-239

Peele TC, Beale OW, Lesesne FF (1970) The physical properties of some South Carolina soils. South Carolina Agricultural Experiment Station Technical Bulletin 1037. Clemson University, Clemson, SC

Sadler EJ, Busscher WJ, Karlen DL (1995) Site-specific yield histories on a SE coastal plain field. In: Robert PC, Rust RH, Larson WE (eds) Site-Specific Management for Agricultural Systems. ASA, CSSA, SSSA, Madison, WI, USA, pp 153-166

Sadler EJ, Camp CR, Evans DE, Usrey LJ (1996) A site-specific center pivot irrigation system for highly-variable Coastal Plain soils. In: Robert PC, Rust RH, Larson WE (eds) Proceedings of the 3rd international conference on precision agriculture, 23-26 June, Minneapolis, MN. ASA/CSSA/SSSA, Madison, WI, pp 827-834

Sadler EJ, Camp CR, Evans DE, Millen JA (2002) Spatial variation of corn response to irrigation. Trans ASAE 45(6):1869-1881

Schwartz RC, Evett SR, Anderson S, Anderson D (2016) Evaluation of a direct-coupled TDR for determination of soil water content and bulk electrical conductivity. Vadose Zone J. https://doi. org/10.2136/vzj2015.08.0115

Shi J, Zuo Q, Li S, Ben-Gal A (2015) An index for plant water deficit based on root-weighted soil water content. J Hydrol 522:285-294

Wu X, Zhang W, Liu W, Zuo Q, Shi J, Yan X, Zhang H, Xue X, Wang L, Zhang M, Ben-Gal A (2017) Root-weighted soil water status for plant water deficit index based irrigation scheduling. Agric Water Manag 189:137-147. https://doi.org/10.1016/j.agwat .2017.04.013

Publisher's Note Springer Nature remains neutral with regard to jurisdictional claims in published maps and institutional affiliations. 